\title{
Comment on: "Willingness to Pay for a COVID-19 Vaccine”
}

\author{
Philipp Sprengholz ${ }^{1}\left[\right.$ Cornelia Betsch ${ }^{1,2}$
}

Accepted: 17 April 2021 / Published online: 11 May 2021

(c) The Author(s) 2021

Based on a Chilean sample ( $N=531)$, Cerda and García [1] recently investigated the willingness to pay (WTP) for vaccination against COVID-19. While 91 participants indicated they would not pay for vaccination, the majority were willing to do so. As higher income increased payment intention, the authors argued that health systems could implement a mix of public and private financing, in which vaccination would be provided free of charge to low-income groups while wealthier individuals would be required to pay.

However, the article fails to fully acknowledge that overall vaccination uptake is likely to decrease if payments were introduced. As the article indicates, those unwilling to pay might choose not to be vaccinated for financial or moral reasons. Additionally, however, some of those who are willing to pay might also refrain if prices were to exceed individual limits related to income as well as the perceived costs and benefits of vaccination [2]. For that reason, we reanalyzed the published data to investigate the potentially detrimental effects of monetary charges on vaccination uptake, especially among those who are willing to pay.

In the original study, one of ten vaccination prices (e.g., an initial charge of US\$101) was randomly suggested to those participants who indicated their general willingness to pay for vaccination. If they indicated a willingness to pay the initial charge, they were asked whether they would be willing to pay a higher charge (e.g., US\$151); alternatively, they were asked whether they would be willing to pay a lower charge (e.g., US\$50). Based on these data, Cerda and García [1] estimated a mean WTP of US\$232. On re-analyzing the data to investigate how many participants would be

This comment refers to the article available online at https://doi. org/10.1007/s40258-021-00644-6.

Philipp Sprengholz

philipp.sprengholz@uni-erfurt.de

1 Media and Communication Science, University of Erfurt, Nordhäuser Str. 63, 99089 Erfurt, Germany

2 Center for Empirical Research in Economics and Behavioral Sciences, University of Erfurt, Erfurt, Germany willing to pay a given price, two gradients were calculated. As shown in Fig. 1, the minimum (maximum) gradient refers to the lowest (highest) proportion of participants willing to pay for vaccination at a particular price. The results indicate that vaccination intention decreases with rising price. While a maximum of $83 \%$ of all participants were assumed willing to be vaccinated for US $\$ 0.01$, vaccination willingness based on the original WTP estimate of US\$232 fell to $24 \%$ (minimum) to 53\% (maximum), and beyond as the price of vaccination increased.

It seems very unlikely that all of those who dropped out at a certain price did so because of limited resources. For that reason, vaccination intention can be expected to decline once a charge is introduced, even with financial support for low-income and vulnerable groups. It follows that vaccination charges would put public health at risk and make it difficult to reach herd immunity. As early research results indicate that vaccination also limits transmission of the coronavirus [3], it is important to achieve high uptake rates to protect those who cannot be vaccinated, and every affordable measure should therefore be implemented to promote vaccination [4]. Consequently, vaccination against COVID19 should be free of charge for everyone, and production/ procurement, distribution, and administration of vaccines should be financed by government (e.g., by using income tax revenues). Where this is not possible, the COVAX initiative can provide international support [5].

As discussed by Cerda and García [1], there is a need for communication measures that emphasize the individual and social risks of COVID-19 and address concerns about the safety and efficacy of the vaccines. Information campaigns can help to foster vaccination intention [6], but vaccination should be free of charge to ensure maximum conversion of intention into action. 


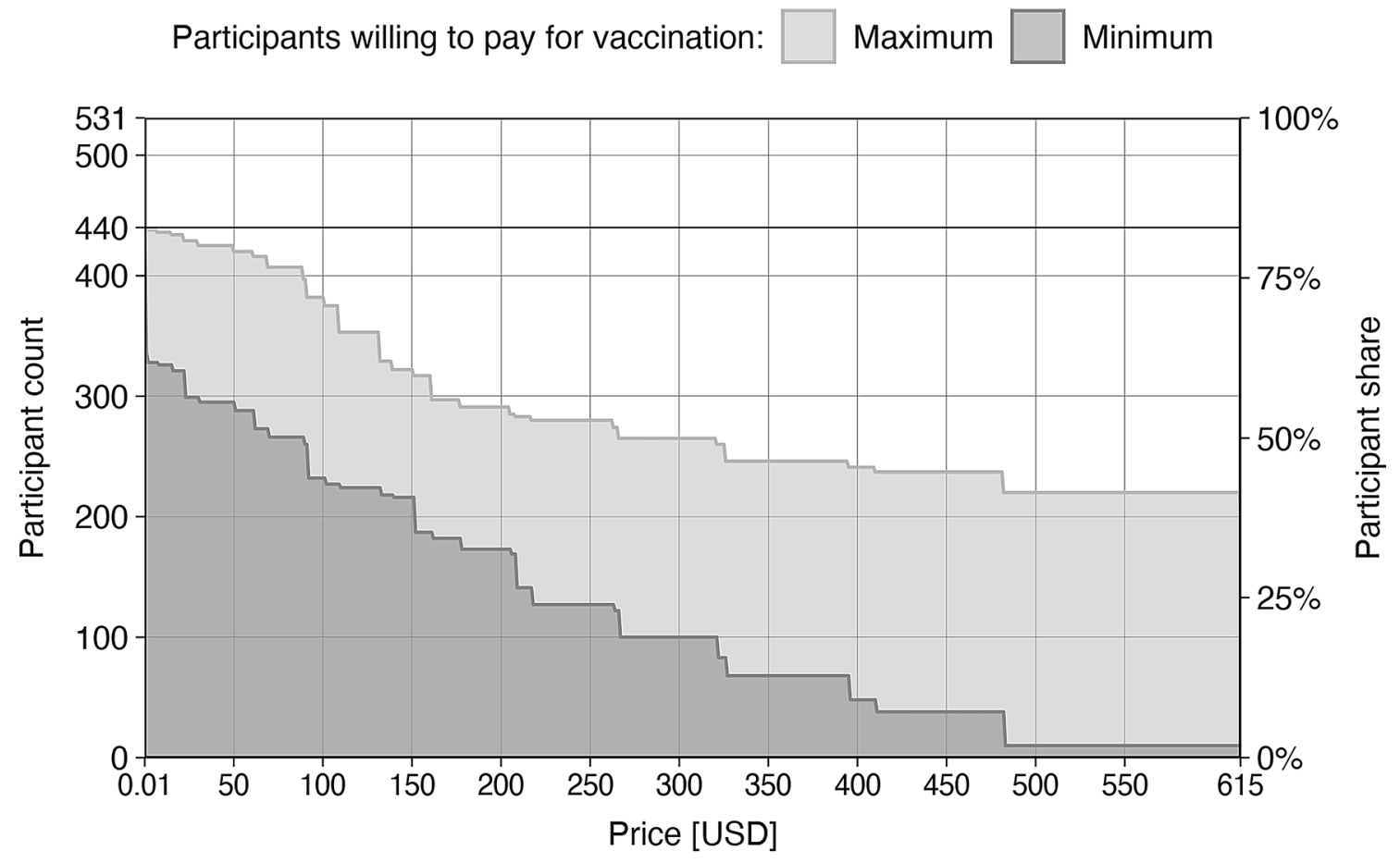

Fig. 1 Willingness to pay for the vaccination against COVID-19. Of 531 participants, 440 indicated their willingness to pay for vaccination. Based on the original experimental data [1], we calculated the minimum and maximum share of participants willing to pay a certain price. For the minimum gradient, participants were considered willing to pay a given price if they accepted at least one of the two offered charges and the price did not exceed the highest accepted charge. For the maximum gradient, participants were considered will-

Authors' contributions PS and CB designed the research; PS planned and performed data analysis, and wrote the initial draft, which was revised and approved by $\mathrm{CB}$.

\section{Declarations}

Funding Open Access funding enabled and organized by Projekt DEAL. This work was supported by the German Research Foundation (BE3970/12-1) and the Klaus Tschira Foundation (no award/grant number).

\section{Conflicts of interest Not applicable.}

Availability of data and material Data are available at https://doi.org/ 10.17605/OSF.IO/XJHC2.

Code availability The data analysis script is available at https://doi.org/ 10.17605/OSF.IO/XJHC2.

Authors' contributions PS and CB designed the research; PS planned and performed data analysis, and wrote the initial draft, which was revised and approved by $\mathrm{CB}$.

Ethics approval Not applicable.

Consent to participate Not applicable. ing to pay a given price if they accepted one or neither of the two charges and the price was less than the lowest rejected charge, or if they accepted both charges. For example, in relation to the US\$200 price tag, a participant who accepted a first charge of US $\$ 177$ but not a second charge of US\$266 was included in the maximum gradient but not in the minimum gradient. The results indicate a steep decline in vaccination intention with rising price

Consent for publication Not applicable.

Open Access This article is licensed under a Creative Commons Attribution-NonCommercial 4.0 International License, which permits any non-commercial use, sharing, adaptation, distribution and reproduction in any medium or format, as long as you give appropriate credit to the original author(s) and the source, provide a link to the Creative Commons licence, and indicate if changes were made. The images or other third party material in this article are included in the article's Creative Commons licence, unless indicated otherwise in a credit line to the material. If material is not included in the article's Creative Commons licence and your intended use is not permitted by statutory regulation or exceeds the permitted use, you will need to obtain permission directly from the copyright holder. To view a copy of this licence, visit http://creativecommons.org/licenses/by-nc/4.0/.

\section{References}

1. Cerda AA, García LY. Willingness to Pay for a COVID-19 Vaccine. Appl Health Econ Health Policy. 2021. https://doi.org/10. 1007/s40258-021-00644-6 (Published Online First).

2. Betsch C, Schmid P, Heinemeier D, et al. Beyond confidence: Development of a measure assessing the 5C psychological 
antecedents of vaccination. PLoS ONE. 2018;13:e0208601. https://doi.org/10.1371/journal.pone.0208601.

3. Petter E, Mor O, Zuckerman N, et al. Initial real world evidence for lower viral load of individuals who have been vaccinated by BNT162b2. medRxiv. 2021. https://doi.org/10.1101/2021.02.08. 21251329 (Published Online First).

4. Attwell K, Lake J, Sneddon J, et al. Converting the maybes: Crucial for a successful COVID-19 vaccination strategy. PLoS ONE. 2021;16:e0245907. https://doi.org/10.1371/journal.pone.0245907.
5. Why a pioneering plan to distribute COVID vaccines equitably must succeed. Nature 2021; 589:170-170. doi:https://doi.org/10. 1038/d41586-021-00044-9

6. Verger P, Dubé E. Restoring confidence in vaccines in the COVID19 era. Expert Rev Vaccines. 2020;19:991-3. https://doi.org/10. 1080/14760584.2020.1825945. 